\title{
Effects of Exposure to Carbon Dioxide and Bioeffluents on Perceived Air Quality, Self- assessed Acute Health Symptoms and Cognitive Performance
}

\author{
Zhang, Xiaojing; Wargocki, Pawel; Lian, Zhiwei; Thyregod, Camilla
}

Published in:

Indoor Air

Link to article, DOI:

10.1111/ina.12284

Publication date:

2017

Document Version

Peer reviewed version

Link back to DTU Orbit

Citation (APA):

Zhang, X., Wargocki, P., Lian, Z., \& Thyregod, C. (2017). Effects of Exposure to Carbon Dioxide and Bioeffluents on Perceived Air Quality, Self-assessed Acute Health Symptoms and Cognitive Performance. Indoor Air, 27(1), 47-64. https://doi.org/10.1111/ina.12284

\section{General rights}

Copyright and moral rights for the publications made accessible in the public portal are retained by the authors and/or other copyright owners and it is a condition of accessing publications that users recognise and abide by the legal requirements associated with these rights.

- Users may download and print one copy of any publication from the public portal for the purpose of private study or research.

- You may not further distribute the material or use it for any profit-making activity or commercial gain

- You may freely distribute the URL identifying the publication in the public portal 
Received Date : 20-Sep-2015

Accepted Date : 23-Jan-2016

Article type : Original Article

\title{
Effects of Exposure to Carbon Dioxide and Bioeffluents on Perceived
}

\begin{abstract}
Air Quality, Self-assessed Acute Health Symptoms and Cognitive Performance
\end{abstract}

Xiaojing Zhang ${ }^{1,2}$, Pawel Wargocki ${ }^{2}$, Zhiwei Lian ${ }^{1}$ and Camilla Thyregod ${ }^{3}$

${ }^{1}$ School of Naval Architecture, Ocean \& Civil Engineering, Shanghai Jiao Tong University, Shanghai, 200240, China. Tel: +86 18801903326.e-mail: xjzhanger@163.com

${ }^{2}$ International Centre for Indoor Environment and Energy, Technical University of Denmark, Kongens Lyngby, DK-2800, Denmark

${ }^{3}$ Department of Applied Mathematics and Computer Science, Technical University of Denmark, Kongens Lyngby, DK-2800, Denmark

\begin{abstract}
The purpose of this study was to examine the effects on humans of exposure to carbon dioxide $\left(\mathrm{CO}_{2}\right)$ and bioeffluents. In three of the five exposures, the outdoor air supply rate was high enough to remove bioeffluents, resulting in a $\mathrm{CO}_{2}$ level of $500 \mathrm{ppm}$. Chemically pure $\mathrm{CO}_{2}$ was added to this reference condition to create exposure conditions with $\mathrm{CO}_{2}$ at 1,000 This article has been accepted for publication and undergone full peer review but has not been through the copyediting, typesetting, pagination and proofreading process, which may lead to differences between this version and the Version of Record. Please cite this article as doi: 10.1111/ina.12284
\end{abstract}

This article is protected by copyright. All rights reserved. 
ppm or 3,000 ppm. In two further conditions, the outdoor air supply rate was restricted so that the bioeffluent $\mathrm{CO}_{2}$ reached $1,000 \mathrm{ppm}$ or $3,000 \mathrm{ppm}$. The same twenty-five subjects were exposed for 255 minutes to each condition. Subjective ratings, physiological responses and cognitive performance were measured. No statistically significant effects on perceived air quality, acute health symptoms or cognitive performance were seen during exposures when $\mathrm{CO}_{2}$ was added. Exposures to bioeffluents with $\mathrm{CO}_{2}$ at 3,000 ppm reduced perceived air quality, increased the intensity of reported headache, fatigue, sleepiness and difficulty in thinking clearly, and reduced speed of addition, the response time in a redirection task and the number of correct links made in the cue-utilisation test. This suggests that moderate concentrations of bioeffluents, but not pure $\mathrm{CO}_{2}$, will result in deleterious effects on occupants during typical indoor exposures.

Key words Carbon dioxide; Human bioeffluents; Acute health symptoms; Perceived air quality; Cognitive performance; Subjective responses

\section{Practical Implications}

Responses of subjects participating in the experiments show no indication that $\mathrm{CO}_{2}$ should be considered harmful with respect to building-related health symptoms, and that it should reduce perceived air quality at concentrations, which are normally encountered indoors. $\mathrm{CO}_{2}$ is simply a good indicator of indoor air quality. Because the present experiment collected responses of young college-age adults, further verification of the results is needed for other groups in population such as elderly and infants. Dose-response relationships between human bioeffluents that include $\mathrm{CO}_{2}$ and indicators of health, wellbeing and performance provide a good basis for stipulating air quality standards and the corresponding ventilation requirements, where the primary pollution sources are the occupants themselves.

This article is protected by copyright. All rights reserved. 


\section{Introduction}

Carbon dioxide $\left(\mathrm{CO}_{2}\right)$ is one of the components of the earth atmosphere. It is also a major human metabolite (bioeffluent). It is a colourless and odourless gas. The background level of $\mathrm{CO}_{2}$ in ambient air is now about $400 \mathrm{ppm}$ and it has been gradually increasing due to industrialization and the consequent release of $\mathrm{CO}_{2}$ from the combustion of fossil fuels; over the last half century it has increased by nearly $80 \mathrm{ppm}$. An outdoor level of $350 \mathrm{ppm}$ has generally been used when determining ventilation requirement in terms of acceptable $\mathrm{CO}_{2}$ levels (e.g., Fanger and Berg-Munch, 1983). The concentration of $\mathrm{CO}_{2}$ in buildings can be one order of magnitude higher than outdoors, typically being below 2,000-2,500 ppm, but in some cases reaching 4,000-4,500 ppm or even higher (e.g., Myhrvold et al., 1996; Stricker et al., 1997; Shaughnessy et al., 2006; Bekö et al., 2010; Menå and Larsen, 2010). A level of 5,000 ppm is used as an occupational exposure limit for $\mathrm{CO}_{2}$ (ACGIH, 2011), so levels of 5,000 ppm and higher are expected to result in toxic effects, if exposure at this level is longer than 8 hours and $\mathrm{CO}_{2}$ is a dominant component of exposure. In the non-industrial indoor environments (e.g., offices, schools and homes), $\mathrm{CO}_{2}$ is not a dominant pollutant such as in occupational settings (e.g., breweries and beverage bottling plants), and the effects of $\mathrm{CO}_{2}$ can be modified by many other pollutants present at low concentrations. The occupational limits may not therefore be directly applicable in non-industrial indoor environments due to potential additive or synergistic effects between different pollutants.

In non-industrial settings, the major source of $\mathrm{CO}_{2}$ is human metabolism. The concentration of $\mathrm{CO}_{2}$ in exhaled air is two orders of magnitude higher than in the ambient air and usually between 40,000 and $55,000 \mathrm{ppm}$. The levels of $\mathrm{CO}_{2}$ that occur indoors thus depend predominantly on human occupancy and on the rate of exchange with outdoor air achieved by natural or mechanical means.

This article is protected by copyright. All rights reserved. 
Since the 19th Century, the indoor $\mathrm{CO}_{2}$ concentration has been used as an indicator of air quality in buildings and the quantity and effectiveness of ventilation with outdoor air (Pettenkofer, 1858). Following Lavoisier (18th century), it was believed that an excess of $\mathrm{CO}_{2}$ due to respiration caused discomfort, rather than a scarcity of oxygen which was termed before Lavoisier as the "igneo-aerial particles". As articulated by Pettenkofer, 'The corruption of the air is not caused by the carbon dioxide content; we simply use this as a benchmark from which we can then also estimate a higher or lower content of other (pollutant) substances.' Recent work by Ramalho et al. (2015) provides some support to the view that $\mathrm{CO}_{2}$ is a good indicator of other pollutants.

It has generally been accepted that indoor $\mathrm{CO}_{2}$ levels at or below $1,000 \mathrm{ppm}$ indicate that the indoor air quality is acceptable (outdoor level of $\mathrm{CO}_{2}$ is then assumed to be $350 \mathrm{ppm}$ ). It makes sense to revise the level of $1,000 \mathrm{ppm}$ according to the outdoor $\mathrm{CO}_{2}$ levels, which since Pettenkofer increased by more than $100 \mathrm{ppm}$ due to industrialization and is now increasing at a fairly high pace.

$\mathrm{CO}_{2}$ has been used quite successfully as an indicator of the required outdoor air supply rate in rooms with occupants present, especially when there is high and variable occupancy, as in theatres and lecture halls (e.g., Emmerich and Persily, 2001). $\mathrm{CO}_{2}$ is used as a control variable in demand-controlled ventilation (DCV) installations, whose main purpose is to reduce the energy consumed by building ventilation (Cable et al., 2014). Studies by Yaglou et al. (1936), Fanger (1988) and many others (Cain et al., 1983; Iwashita et al., 1990) show that when the air is polluted mainly by human bioeffluents such that the $\mathrm{CO}_{2}$ level is $1,000 \mathrm{ppm}$, this air causes visitors entering the space to report moderate odour intensity; about $20 \%$ find the indoor air quality to be unacceptable. Current ventilation standards are based mainly on these studies, but they also allow for the possibility that poor air quality might in some cases be caused by pollutants other than human bioeffluents (ASHRAE, 2013; EN, 2007).

This article is protected by copyright. All rights reserved. 
In numerous field studies, measured $\mathrm{CO}_{2}$ has been associated with subjectively assessed acute health symptoms (e.g., Seppänen et al., 1999; Apte et al., 2000; Erdmann et al., 2002). Significant associations were observed with headache, fatigue, eye, nose and respiratory tract symptoms even in buildings where $\mathrm{CO}_{2}$ levels were below 5,000 ppm; the prevalence of symptoms continued to decrease with the $\mathrm{CO}_{2}$ level even below 800 ppm (e.g., Myhrvold et al., 1996; Seppänen et al., 1999; Tsai et al., 2012; Norbäck et al., 2013). In these studies, $\mathrm{CO}_{2}$ was not considered to be a causative agent, but as an indicator of exposure to pollutants and of the adequacy and efficiency of the ventilation. In other words, $\mathrm{CO}_{2}$ was not considered in these studies to be a pollutant but rather as a harmless indicator of the presence of harmful pollutants. The pollutants responsible for the effects observed were seldom identified, not even those causing a specific group of symptoms. These pollutants usually have indoor sources and could be emissions from building or furnishing materials or emissions from occupants (human bioeffluents).

Raised $\mathrm{CO}_{2}$ levels have also been associated with a decrease in human performance, especially in studies in schools, where there is usually high occupancy and a low ventilation rate and the main pollution source is the occupants (e.g., Myhrvold et al., 1996; Myhrvold and Olesen, 1997; Milton et al., 2000; Coley et al., 2004; Bakó-Biró et al., 2008; HaverinenShaughnessy et al., 2011; Mendell et al., 2013): the performance of many psychological tests examining various cognitive skills and academic performance, and even absenteeism, were all affected negatively when $\mathrm{CO}_{2}$ levels were high. No causative agent has yet been identified. An insufficient outdoor air supply rate for the purpose of diluting and removing any causative agents has been hypothesised to be the main cause of the effects observed, which again underlines that $\mathrm{CO}_{2}$ is simply an indicator of insufficient ventilation.

Published toxicological studies agree that only $\mathrm{CO}_{2}$ at much higher levels than those typically occurring indoors can produce harmful effects. For example, the study by Law et al.

This article is protected by copyright. All rights reserved. 
(2010) shows that only levels of 10,000 ppm or higher can cause toxic effects during relatively short exposures. Although these findings were obtained in highly specialized environment, they are compatible with the postulation of Pettenkofer that $\mathrm{CO}_{2}$ at levels occurring indoors could be considered as harmless.

Three recent experiments provide new evidence on the issue of the role of $\mathrm{CO}_{2}$ in nonindustrial environments: they appear to show that exposures to pure $\mathrm{CO}_{2}$ even at levels $<5,000 \mathrm{ppm}$ (typically occurring indoors) can potentially result in negative effects on some health symptoms and on some types of cognitive performance (Kajtár and Herczeg, 2012; Satish et al., 2012; Allen et al., 2015). A study by Kajtár and Herczeg (2012) showed that performance of proof-reading was negatively affected when 10 subjects were exposed for 2 to 3 hours to elevated levels of $\mathrm{CO}_{2}$ at 3,000 ppm obtained by adding $\mathrm{CO}_{2}$ into the chamber. They also observed increased diastolic blood pressure and decreased mid-frequency components of heart rate variability, which they considered to be the evidence for increased stress and arousal. In the study by Satish et al. (2012), 22 subjects were exposed for 2.5 hours to three levels of pure $\mathrm{CO}_{2}$ added to the chamber from a cylinder. They observed a systematic reduction in performance of a complex test involving decision-making that was performed for 1.5 hours, when $\mathrm{CO}_{2}$ was increased from 600 ppm to 1,000 or 2,500 ppm; the effect was statistically significant at 2,500 ppm and more pronounced for those aspects of the test with high cognitive demand, as indicated by effects on measures of information utilisation, breadth of approach and basic strategy. Perceived air quality and the health symptoms reported by subjects were collected in this study but not reported in the published paper. No physiological measurements were performed by Satish et al. (2012). Allen et al. (2015) obtained similar results pertaining to performance of decision-making test as in the study by Satish et al. (2012). They exposed 24 subjects for 8 hours to $\mathrm{CO}_{2}$ levels at $550 \mathrm{ppm}$, $945 \mathrm{ppm}$ and 1,400 ppm, the higher levels were obtained by adding pure $\mathrm{CO}_{2}$ from a 
cylinder. They observed that several domains of the decision-making tests decreased significantly and by a very high degree during exposure to $\mathrm{CO}_{2}$ at $945 \mathrm{ppm}$ and $1,400 \mathrm{ppm}$ compared with the levels of $550 \mathrm{ppm}$, i.e. the negative effects were seen at levels even lower than these examined by Satish et al. (2012). The results of these three studies appear to indicate that $\mathrm{CO}_{2}$ should not only be considered as an indicator of poor indoor air quality but also as a pollutant itself. Further studies are required to support or reject this postulation, as it is based only on these three experiments and is not supported by any previous research.

Although Yaglou et al. (1936), Cain et al. (1983), Fanger (1988) and Iwashita et al. (1990) examined the effects of human bioeffluents on perceived air quality, very few experiments have attempted to isolate the effects of bioeffluents on acute health symptoms and performance from the effects caused by exposures to other pollutants. The literature reporting an association between $\mathrm{CO}_{2}$ and acute symptoms does not attribute the observed effects only to human bioeffluents but acknowledges that many other pollutants could have contributed to the observed effects, stating only that where the dominant source of pollution is the occupants, the main effects observed seem likely to have been due to exposure to bioeffluents. However, it cannot be precluded that the effects observed in these spaces might have been caused by pollutants other than those emitted by humans. For example, StrømTejsen et al. (2008) showed that the intensity of self-estimated acute health symptoms of eye and nasal irritation, skin dryness, headache, dizziness and mental tension increased during exposures to human bioeffluents when ozone was added to the room air they occupied (an effect likely to be due to the products of reactions between moderate levels of ozone and skin oils). The recent study by Maddalena et al. (2015) sheds a new light on the effects of bioeffluents on different human outcomes, because they deliberately separated exposure to human bioeffluents from exposure to emissions from building materials. They showed that, when 16 subjects were exposed for 4 hours to bioeffluents with $\mathrm{CO}_{2}$ at $1,800 \mathrm{ppm}$, there was

This article is protected by copyright. All rights reserved. 
a significant reduction in their decision-making performance compared with 900 ppm, although there were no differences between conditions in the subjectively reported perception of air quality or acute health symptoms. Although statistically significant, the magnitude of the effects on decision-making performance in this study was modest and considerably lower than had been observed during exposure to pure $\mathrm{CO}_{2}$ in the study by Satish et al. (2012) that used the same performance test. Maddalena et al. did not suggest the possible reasons for this discrepancy, but a careful comparison of the two experiments suggests that it could be due to the selected exposure levels: 900 vs 1,800 ppm in the study by Maddalena et al. and 600 vs 1,000 vs 2,500 ppm in the study by Satish et al., so that the span in $\mathrm{CO}_{2}$ levels was twice as high in the study by Satish et al. The discrepancy could also be due to a difference in the skills of the subjects participating in these two experiments: in the study by Maddalena et al., subjects performed poorly even at $900 \mathrm{ppm}$, especially in aspects of the test with low-tomoderate cognitive demand. The study by Maddelena et al. can be considered as only partially confirming the results by Satish et al., while still providing no indication of an underlying mechanism. More research work on the effects of $\mathrm{CO}_{2}$ and bioeffluents on human responses is required, to examine which levels can cause any negative effects during indoor exposures indoors.

The main purpose of the present paper was to provide further evidence on whether exposure to human bioeffluents and $\mathrm{CO}_{2}$ at levels typically occurring indoors, could result in any discomfort due to poor air quality, acute health symptoms, and reduced performance of cognitive tests and tasks typical of work performed in offices, or cause measurable physiological responses. The results of physiological responses are reported in another paper (Zhang et al., 2016) describing the same experiment, where the potential mechanisms underlying the observed effects are as well discussed.

This article is protected by copyright. All rights reserved. 


\section{Methods}

Approach

Subjects were exposed in a climate chamber to different levels of $\mathrm{CO}_{2}$ and bioeffluents in a design balanced for order of presentation. They were blind to conditions. During the exposures, they assessed their comfort, reported their acute health symptoms and rated their levels of effort and performance. They also performed various cognitive tasks resembling office work. Measurements were carried out to observe changes in their physiological reactions during each exposure.

\section{Facilities}

The experiment was carried out in a $3.6 \times 2.5 \times 2.5 \mathrm{~m}$ stainless steel chamber $\left(30 \mathrm{~m}^{3}\right.$ volume with recirculation ducts) (Fig. 1), which was described in detail by Albrechtsen (1988). The construction minimises the emissions and sorption of pollutants and ensures that the chamber volume is tightly sealed. The chamber has its own system for supplying and conditioning outdoor air, in which the ducting but not the air handling unit itself is also made of stainless steel. The chamber volume is ventilated through a perforated floor with a sub-floor plenum. The air is exhausted through four outlets in the ceiling. A piston-type flow and recirculation ensure that the air is well mixed throughout the entire volume during the exposures; this was verified prior to the present experiments. Immediately prior to the present experiments, the chamber and the plenum were thoroughly cleaned with 'neutral' cleaning agent and 'baked' for one week at $40^{\circ} \mathrm{C}$ to reduce any potential residual pollution adsorbed on the surfaces in contact with chamber air. The G3/F7 particle filters in the supply ducts were newly installed prior to the experiments. No other particle filters or charcoal filters were in place. No scrubbing of the air was performed in the climate chamber in any of the exposure conditions studied. No chemical measurements were made prior to the present experiments to prove that

This article is protected by copyright. All rights reserved. 
the actions described above had removed any residual pollution or that the background pollution levels in the chamber were negligible, but similar actions taken in previous studies have been shown to be sufficient to achieve this goal (Fang et al., 1998a,b). The results obtained in the present experiment support the claim that the background pollution in the chamber was low (see Results section). The chamber is quite small and ascetic in appearance. It does not resemble typical indoor spaces. It was therefore decorated with brightly coloured pictures depicting spacious open plan offices (Fig. 1). There were six workstations in the chamber for the subjects and the experimenter, each consisting of a table, a chair, a laptop PC and a desk lamp.

This article is protected by copyright. All rights reserved. 

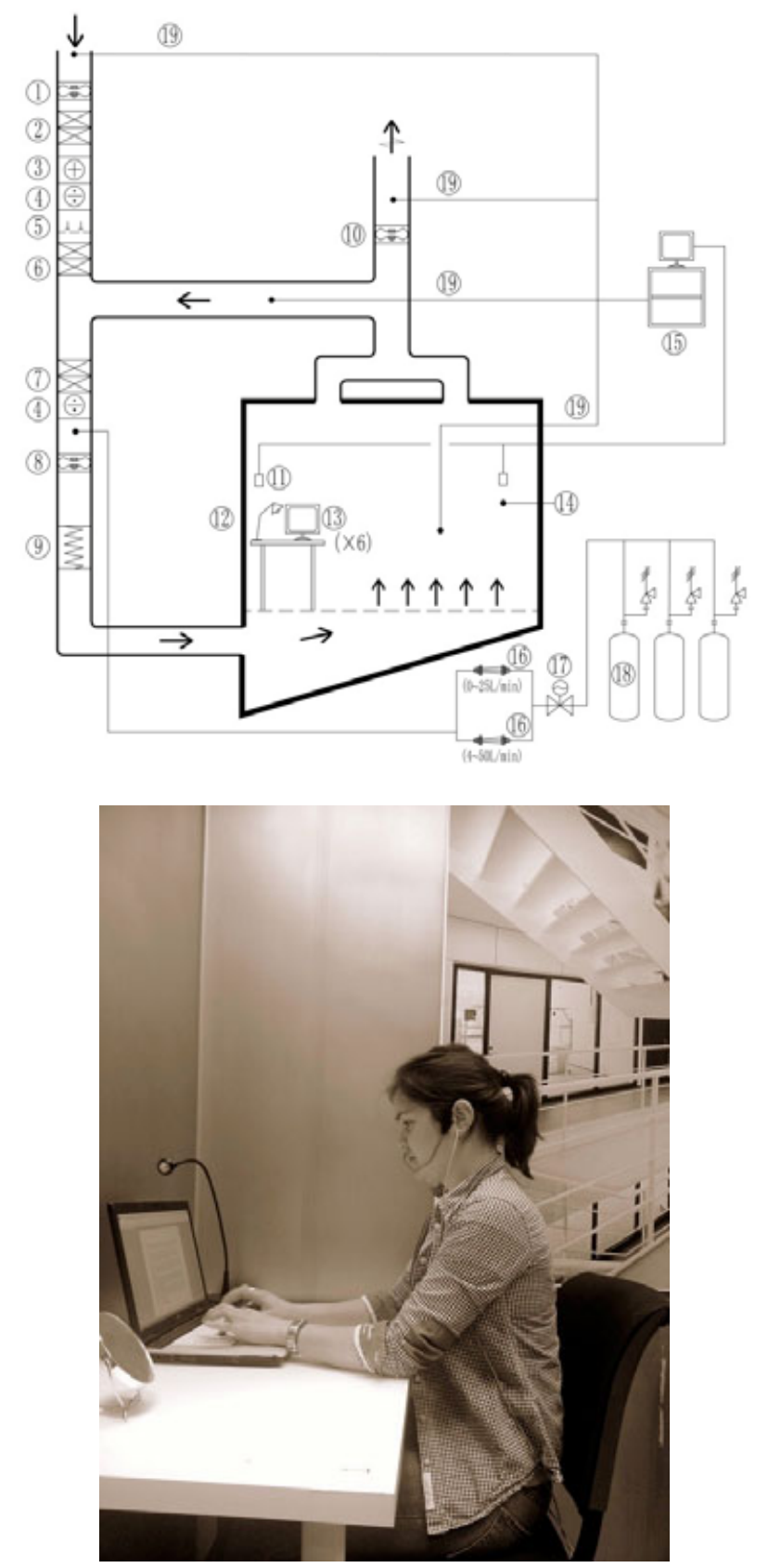

Fig. 1 Schematic figure of the chamber, where the experiments were carried out (left) and a view of the inside of the chamber (right):(1) supply fan, (2) two stage filter G3/F7, (3) heating coil, (4) cooling coil, (5) dampers, (6) filter box for charcoal filters (empty), (7) filter box (empty), (8) recirculating fan, (9) electric heating coil, (10) exhaust fan, (11) HOBO logger (temperature \& relative humidity sensor) with $\mathrm{CO}_{2}$ sensor, (12) desk lamp, (13) laptop, (14) 
temperature and humidity sensor of the chamber control system, (15) multi-gas analyzer, (16)

flowmeters, (17) pressure regulator, (18) $\mathrm{CO}_{2}$ gas cylinders (30L), (19) sampling point

\section{Subjects}

A power analysis was performed to estimate the minimum number of subjects that would have to participate in the experiment to achieve significant differences in the dependent variables at the $(\mathrm{P}<0.05)$ level (Lan and Lian, 2010). Assuming a within-subject design with repeated measures, a statistical power of 0.8 in general, an effect size of 0.4 estimated from a previous study (Lan and Lian, 2010), the correlation among measures to be 0.5 by default, and a non-sphericity correction to be 0.25 (Lan and Lian, 2010), the minimum number of subjects required was estimated with $\mathrm{G}^{*}$ power software to be 25 persons. Twenty-five subjects were recruited to ensure a balanced design. They were all students recruited through advertisements placed on the university campus. All subjects were volunteers. Ten males and fifteen females were included with a mean age of $23 \pm 2$ (mean \pm SD) years old, mean height of $173 \pm 11 \mathrm{~cm}$ and mean weight of $74.9 \pm 21.8 \mathrm{~kg}$. They were all non-smokers. The intention of the present work was to examine the responses of healthy adults (young students), but it appeared that they were difficult to recruit. Therefore, subjects participating in the experiments included atopic individuals, as well as persons considering themselves sensitive to indoor air quality. Eight subjects reported that they were atopic (one subject reported to have asthma, allergy and eczema, one asthma and allergy, three allergy, two hayfever, and one eczema). Among them, three considered themselves to be additionally sensitive to indoor air quality. By chance, the proportion of atopic subjects (32\%) in the present experiment was slightly higher than that in the general population of Denmark, which according to Masoli et al. (2004) is $24 \%$. No subjects exhibited symptoms of allergy, asthma, hayfever or eczema during experiments. Twelve subjects reported that they were sensitive to indoor air quality,

This article is protected by copyright. All rights reserved. 
and eight that they were sensitive to heat, cold, light and/or noise. None reported to suffer from chronic disease. The information on chronic diseases, atopy and sensitivity was collected through the questionnaire distributed to subjects upon recruitment. It was not verified using clinical measurements or objective tests whether the atopic subjects were atopic, and whether the subjects considering themselves to be sensitive to air quality were indeed sensitive. All of the subjects were Danish and could speak English fluently. They were paid DKK 130.45 per hour (ca. US\$23) for taking part in the experiments. All subjects gave written and informed consent to their participation in the experiments.

\section{Experimental Conditions}

Five exposure conditions were created.

In the background condition (referred to as 'B500'), the chamber was ventilated at an outdoor air supply rate of $720 \mathrm{~m}^{3} / \mathrm{h}$ (corresponding to $24 \mathrm{~h}^{-1}$ ) so that the bioeffluents and $\mathrm{CO}_{2}$ could be kept sufficiently low with five subjects and an experimenter present in the chamber. At this ventilation rate the $\mathrm{CO}_{2}$ concentration was estimated to be $500 \mathrm{ppm}$.

In two exposures, chemically pure $\mathrm{CO}_{2}$ was added artificially to the supply air to reach levels of 1,000 ppm (referred to as 'P1000') or 3,000 pm (referred to as 'P3000'). 1,000 ppm was selected because it is generally considered to be an indicator of the limit for acceptable indoor air quality as indicated in the Introduction. 3,000 ppm was selected because it is well below the current occupational limit of 5,000 ppm. The selection was also based on the practical feasibility of reaching a $\mathrm{CO}_{2}$ level of $3,000 \mathrm{ppm}$, when the sole source of $\mathrm{CO}_{2}$ was human metabolism. The intention was additionally to examine a $\mathrm{CO}_{2}$ concentration slightly higher than was used by Satish et al. (2012). During these exposure conditions, the chamber was ventilated at the same outdoor air supply rate as in the background condition to keep the $\mathrm{CO}_{2}$ and other bioeffluents from the occupants of the chamber low (Table 1). To reach $\mathrm{CO}_{2}$ 
concentrations of $1,000 \mathrm{ppm}$ and $3,000 \mathrm{ppm}$, pure $\mathrm{CO}_{2}(99.99 \%$ in quality) was bled from cylinders into the supply duct and mixed with the incoming outdoor air (Fig. 1). A pressure regulator kept the pressure constant and calibrated flow meters were used to determine the dosage of $\mathrm{CO}_{2}$.

In two further exposures, the outdoor air supply rate to the chamber was restricted so that the $\mathrm{CO}_{2}$ concentration from five subjects and an experimenter in the chamber was either 1,000 $\mathrm{ppm}$ (referred to as 'M1000') or 3,000 ppm (referred to as 'M3000') (Table 1). This ensured that other bioeffluents reached concentrations corresponding to those in occupied rooms with $\mathrm{CO}_{2}$ at these levels (Table 1). To make a preliminary estimate of the airflow in the chamber it was assumed that an average-sized adult engaged in office work produces about $0.0052 \mathrm{~L} \mathrm{CO}_{2}$ per second (ASTM, 2012). To establish these two exposure levels of bioeffluents instantly from the time the subjects entered the chamber, a group of five other people were present in the chamber immediately prior to each exposure to build up the concentration to the required $\mathrm{CO}_{2}$ level. They left the chamber immediately before the subjects entered the chamber, but the subjects did not see them, in order to ensure that subjects remained blind to exposures.

Table 1 shows that the resulting levels of $\mathrm{CO}_{2}$ in the chamber originated from 3 different sources: dosed from the cylinders, brought from the outdoor air itself, and emitted by the occupants, in descending order of magnitude. Real-time $\mathrm{CO}_{2}$ measurements were made to ensure that the intended concentrations of $\mathrm{CO}_{2}$ were reached and maintained throughout each exposure (measured outdoor levels of $\mathrm{CO}_{2}$ were in the range of 350-380 ppm during the experiments). Temperature and noise level were kept constant during the exposures. However, due to the lack of a dehumidifier, the relative humidity $(\mathrm{RH})$ increased by a few $\%$ at M3000.

This article is protected by copyright. All rights reserved. 
Table 1 Planned conditions for different exposures

\begin{tabular}{ccccccc}
\hline Condition & $\begin{array}{c}\text { Outdoor air } \\
\text { supply rate to } \\
\text { the chamber } \\
\left(\mathrm{m}^{3} / \mathrm{h}\right) \\
/\end{array}$ & $\begin{array}{c}\mathrm{CO}_{2} \\
\text { transported } \\
\text { with } \\
\text { outdor air } \\
(1 / \mathrm{m} \text { per person) }\end{array}$ & $\begin{array}{c}\text { Pure } \mathrm{CO}_{2} \\
\text { dosed from } \\
\text { cylinders } \\
(1 / \mathrm{min})\end{array}$ & $\begin{array}{c}\text { Metabolic } \\
\mathrm{CO}_{2} \text { generated } \\
\text { by people in } \\
\text { the chamber } \\
(1 / \mathrm{min})\end{array}$ & $\begin{array}{c}\mathrm{CO}_{2} \text { level } \\
\text { in the } \\
\text { chamber } \\
\text { (outdoor } \\
\text { evel at } 350 \\
\text { ppm })\end{array}$ & $\begin{array}{c}\text { Temperature } \\
\mathrm{RH} \\
\text { Noise level }\end{array}$ \\
\hline B500 & $720 / 33.3$ & 4.2 & - & 1.9 & 500 & \\
P1000 & $720 / 33.3$ & 4.2 & 6 & 1.9 & 1000 & $24^{\circ} \mathrm{C}$ \\
P3000 & $720 / 33.3$ & 4.2 & 30 & 1.9 & 3000 & $30 \%$ \\
M1000 & $155 / 7.2$ & 0.9 & - & 1.9 & 1000 & $45 \mathrm{~dB}(\mathrm{~A})$ \\
M3000 & $38 / 1.8$ & 0.2 & - & 1.9 & 3000 & \\
\hline
\end{tabular}

Measurements

$\mathrm{CO}_{2}$ concentrations were monitored continuously with a factory-calibrated Innova 1312 photo-acoustic multi-gas monitor (Luma-Sense Technologies A/S, Denmark) with a detection limit of $5.10 \mathrm{ppm}$ and a repeatability of $1 \%$. The $\mathrm{CO}_{2}$ concentration inside the chamber was additionally monitored every five minutes with calibrated $\mathrm{CARBOCAP}{ }^{\circledR} \mathrm{CO}_{2}$ monitors (GMW22,Vaisala, Finland) with a measuring range of $0-5,000 \mathrm{ppm}$ and an accuracy of $\pm 2 \%$ of range $+2 \%$ of reading, and a response time of 1 min. A HOBO U12-013 data logger (Onset Computer Corp., USA) was connected to the $\mathrm{CO}_{2}$ monitor to record the data. This unit also logged the temperature (measurement range of $0-50^{\circ} \mathrm{C}$ and an accuracy of $\pm 0.35^{\circ} \mathrm{C}$ ) and relative humidity (measurement range of $10-90 \%$ and an accuracy of $\pm 2.5 \%$ ). Two measuring units consisting of a carbon dioxide monitor and a data logger were mounted in the chamber at the head height of the seated subjects $(1.1 \mathrm{~m})$. Ozone levels in the chamber were monitored continuously with a calibrated ozone monitor, Model 205 by $2 \mathrm{~B}$ Technologies Inc. (measurement range of $1 \mathrm{ppb}$ to $250 \mathrm{ppm}$ and an accuracy of $\pm 2 \%$ of reading). Spot measurements of light and noise were carried out at the end of the experiment. The lighting intensity was measured with a lux meter Testo 540 (measurement range of 0-99,999 lux and

This article is protected by copyright. All rights reserved. 
an accuracy of $\pm 3 \%$ by Testo AG) and the noise level was measured with a digital sound level meter (measurement range of $35-130 \mathrm{~dB}(\mathrm{~A})$ and an accuracy of $1.5 \mathrm{~dB}(\mathrm{~A})$ by EXTECH). It should be noted that the accuracy specifications of the measuring instruments provided in the paper are the specifications provided by manufacturers and were not verified.

Pen and paper questionnaires were used to collect subjective ratings. They included questions regarding conditions in the chamber, with questions on air quality, odour, thermal sensation, thermal comfort, perceived air freshness, brightness, noise level and air dryness, and questions asking for information on the intensity of acute health symptoms such as dry nose, dry throat, dry skin, dry eye, aching eyes, headache, dizziness, fatigue, difficulty in thinking and concentrating, depression and sleepiness, questions assessing sleepiness (Åkerstedt and Gillberg, 1990), and questions allowing subjects to report their self-estimated performance, the effort they exerted and their attitude to work. The responses of subjects were obtained using visual analogue scales (VA-scales) (Wyon, 1994; Wargocki et al., 1999, 2000); some of which are shown in Fig. 2. Perceived Air Quality was recorded using a continuous scale describing the acceptability of air quality; the scale is divided in the middle to force subjects to rate the air as either acceptable or not acceptable (Wargocki, 2004). The intensity of odour was measured using the 6-point continuous scale introduced by Yaglou et al. (1936). The acceptability of the thermal environment was assessed with the same scale as for the acceptability of the air quality while thermal sensation was obtained using the 7-point scale (ASHRAE, 1997). All scales were presented to the subjects in Danish.

This article is protected by copyright. All rights reserved. 


\section{Assess your work:}

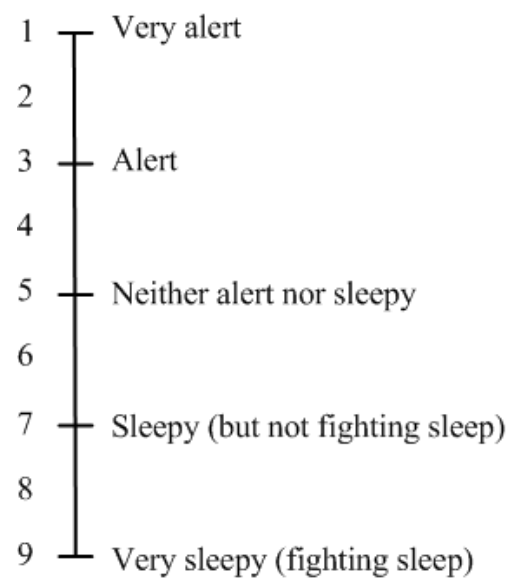

The work seemed:

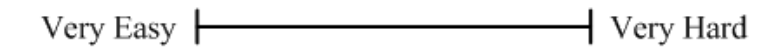

My level of effort was:

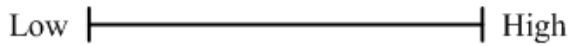

The time pressure was:

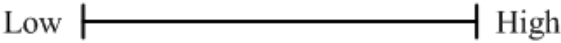

I worked at:

My performance was:

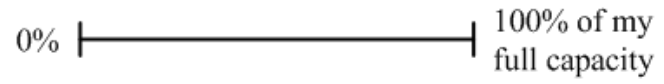

Poor

Fig. 2 Questionnaires used to evaluate sleepiness using the Karolinska Sleepiness Scale (Åkerstedt and Gillberg, 1990) (left) and work performance (right); the scales used to indicate the intensity of symptoms had a format similar to those shown on the right

During the exposures, the subjects performed multiple tasks resembling office work including text typing, arithmetical calculations, and proof-reading (Wargocki et al., 1999; 2000). They also performed different tests to examine the effects of exposures on basic cognitive functions, such as attention level, memory capacity and reaction time, to explore the potential underlying neuro-behavioural and psychological mechanisms. The tests included neuro-behavioural tests comprising of redirection test, grammatical reasoning test, Stroop test, and Stroop test with feedback (Lan et al., 2011). Tsai-Partington test was used to examine the cue-utilization capacity (Partington, 1949; Partington and Leiter, 1949); the performance of this test can be used to predict arousal/stress level. d2 test was used to examine attention and concentration levels of the subjects (Brickenkamp et al., 2010; Twardella et al., 2012). All tests and tasks were pen-and-paper except for the text typing task and the neuro-behavioural tests, which were performed on the laptops. All tests and tasks

This article is protected by copyright. All rights reserved. 
were self-paced except for the d2 test. They were presented in Danish except for the neurobehavioural tests, which were presented in English.

In the text typing tasks, subjects spent 10 min retyping a printed text onto the PC using Microsoft Word; the number of characters typed per minute and the error rate were calculated as the measures of performance. The error rate was estimated by calculating the Levenshtein distance, which is a measure of the difference between two strings of characters (Levenshtein, 1966). The arithmetic tasks consisted of addition and subtraction. Subjects spent 35 min on addition and 15 min on subtraction. In the addition task, subjects added five two-digit numbers printed in the same vertical column; in the subtraction task, subjects subtracted two three-digit numbers; the number of units completed per minute and the error rate were calculated as the measures of performance. The error rate was calculated as the ratio of incorrectly calculated units to all units completed. In the proof-reading task, subjects spent 30 min checking a printed text for error. They were asked to highlight the errors without correcting them. Four types of errors had been inserted in the text, including spelling errors, grammatical errors in the immediate phrase or in the wider context of the text and logical errors. The number of lines read per minute, the error rate and the number of false positives were calculated as the measures of performance. Error rate was calculated as the ratio of missed errors to all errors present in the text while false positives were the number of incorrectly identified errors.

The neuro-behavioural tests were applied in a battery in the following sequence: redirection test, digit span memory test, Stroop test, grammatical reasoning test and Stroop test with feedback. It took subjects about 15 minutes to complete all tests. In the redirection test, the person in the image was equally often showing his face or back, in random order, and was holding the disc in the right or left hand. The task was to state whether the disc was on the right or left hand of the person in the image. In the digit span memory test, a string of 
numbers was sequentially displayed on the screen, each number for one second. The subjects recalled and reproduced the strings according to their sequence after all numbers were displayed; the string of numbers was gradually increased in length as subjects proceeded in the test until two successive errors were made. In the Stroop test, the subjects saw the name of a colour presented in a different colour. The task was to indicate, in successive periods, either the name or the colour of the word presented on the screen by clicking the corresponding colour button on the computer screen. Whether the subjects had to indicate the name or the colour of the word was randomly assigned by the software. In the grammatical reasoning test, three symbols were displayed together with two statements describing the order of the three symbols. The subjects judged whether the statements were True or False. In the Stroop with feedback, the subjects could not proceed to the next screen unless they provided the correct answer. Response time and error rate were recorded in each test except for the digit span memory test and the Stroop test with feedback. In the former test the number of strings recalled correctly and incorrectly and the length of the longest strings recalled were recorded, and for the latter only response time was recorded. Error rate was calculated as the ratio of errors made to all attempts made.

In the Tsai-Partington test, subjects were asked to trace a line as quickly and accurately as possible through a series of 2-digit numbers scattered randomly over a page, essentially rankordering them in sequence. The time allowed was $40 \mathrm{~s}$, which is too short for it to be possible to link all the numbers; the total number of correct links was counted as the measure of performance. In the $\mathrm{d} 2$ test, subjects were given an A4 size page consisting of 658 characters (14 rows of 47 characters). These characters were two consonants, 'd' and 'p', accompanied with dots above and/or below them. The number of dots varied from 1 to 4 . The subjects were asked to identify and mark as many as possible of the ' $\mathrm{d}$ ' characters that were accompanied by two dots; 20s was given for each row. The number of characters processed 
per minute was calculated as an indicator of speed; the number of total errors (TE, defined as the sum of missed characters and false positives) were used as an indicator of accuracy; concentration output $(\mathrm{CO}$, defined as the number of characters processed minus number of total errors) and concentration performance ( $\mathrm{CP}$, defined as the number of correctly marked characters minus number of incorrectly marked distractors) were calculated as indicators of overall concentration level (Brickenkamp et al., 2010; Twardella et al., 2012).

Physiological parameters describing functioning and changes in the respiratory system and the cardiovascular system were measured during the experiments. They included continuous measurements of heart rate, repeated measurements of blood pressure and of the obstruction of the upper respiratory tract (nose and airways) immediately prior to and after the exposure, four repeated measurements of breathing rate overlapping each text typing test, and five repeated measurements of end-tidal $\mathrm{CO}_{2}\left(\mathrm{ETCO}_{2}\right)$ concentration in exhaled air and the oxygen saturation of blood $\left(\mathrm{SPO}_{2}\right)$ before the exposure and after each hour of the exposure, when subjects were taking a short pause before performing the next task. Samples of saliva were collected before and after the exposure for subsequent analysis of cortisol and alpha amylase. As the results of these physiological measurements will be reported in a separate paper, no further details of these measurements are provided here.

\section{Experimental Procedure}

The experiment was conducted from February to April 2014. The selected subjects were randomly assigned to 5 groups, each composed of 5 subjects. Each group participated in the experiments for one week from Monday to Friday. The groups were exposed to different conditions in a Latin square design balanced for order of presentation; full balancing was possible as there were 5 exposure conditions, 5 groups of subjects and the exposures were on 5 consecutive days in each week. Each group took part in a practice and instruction session 
on the Friday or Thursday prior to the week in which their exposures took place; during this session the subjects received all necessary information regarding the procedures, practiced all the tasks and made assessments using all questionnaires, and all the physiological measurements were performed. They were also asked to adjust their clothing so that they felt thermally neutral. They were then requested to wear similar garments on all experimental days; the mean thermal insulation of the clothing was estimated to be 0.75 clo.

Each day, the 5 subjects arrived in the afternoon at 13:00 and completed the experiments by 18:00 (Fig. 3). Immediately upon arrival on the experimental day, the physiological measurements were carried out and once they had been completed the subjects entered the chamber. Each exposure in the chamber lasted 255 minutes. During this period they performed the tests described above and made their subjective evaluations. Several physiological data were also monitored. When in the chamber, the subjects were not allowed to talk to each other, or to use the Internet, cellular phones or any other equipment. The subjects were not allowed to bring any food or drink. They could drink non-carbonated water and eat the biscuits provided to them by the experimental team. They were reminded to adjust their clothing so as to remain thermally neutral. In the middle of each exposure, there was a short break during which subjects could briefly leave the chamber if they needed to go to the restroom; this brief intermission did not measurably influence the exposure levels in the chamber. After the 255-minute exposure subjects left the chamber and the physiological measurements were performed once again. When these measurements had been completed, the subjects re-entered the chamber to re-assess the air quality and odour intensity in the chamber as a visitor, after which they left the premises.

The subjects were asked to avoid spicy food, the consumption of alcohol and any strenuous activities on the day prior to an experimental day or on the day itself. They were asked not to wear strong perfumes or to use strongly perfumed hygienic products on any experimental

This article is protected by copyright. All rights reserved. 
day. The study fell under the Ethics Review Board approval granted to the International Centre for Indoor Environment and Energy (KA04741) for exposure to conditions that commonly occur in buildings in non-intrusive field or laboratory experiments.

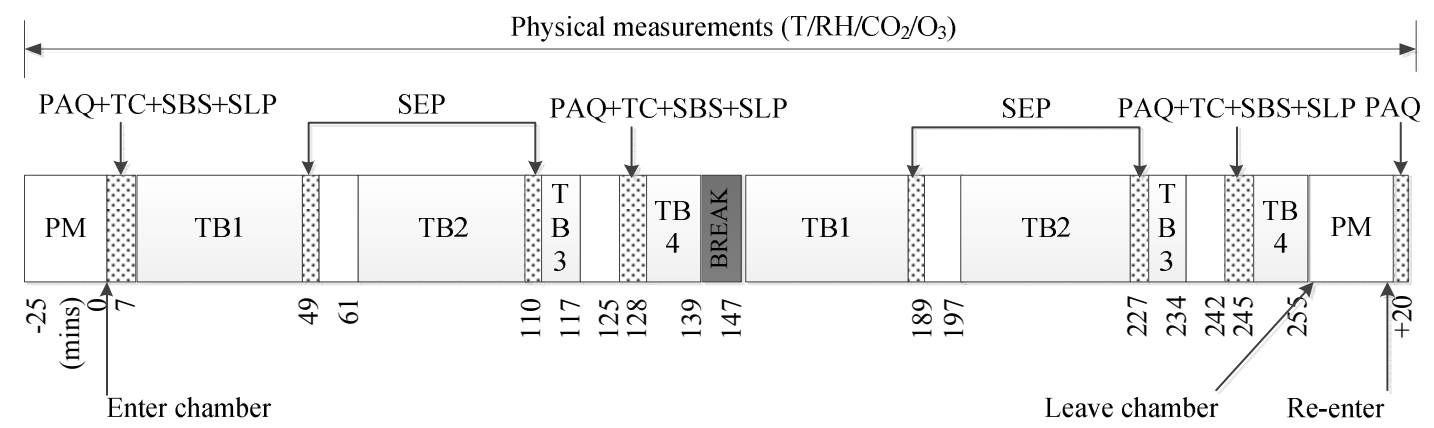

Fig. 3 Experimental procedure, where PAQ/TC/SBS/SLP stands for assessments of perceived air quality, thermal condition, acute health symptoms and sleepiness; SEP stands for selfestimated performance; PM stands for physiological measurements; TB stands for test battery, TB1 includes text typing, proof-reading, TB2 includes neuro-behavioural tests and arithmetical calculations, TB3 includes $\mathrm{d} 2$ test and Tsai-Partington test, TB4 includes text typing; $\mathrm{T}$ stands for temperature

\section{Statistical Analysis}

Firstly, measures of central tendency and variance were obtained for all of the parameters measured or assessed by the subjects after all data had been checked for obvious errors. Descriptive statistics for all outcomes, including mean and standard error (SE), are shown in Table S1 - Table S3 in the Supplementary Material. A mixed ANOVA model was then applied assuming that the residuals were normally distributed. As some of the outcomes are proportions (or percentages), such as the error rates of addition, it would be natural to consider a model based on the binomial distribution for these outcomes. However, the results

This article is protected by copyright. All rights reserved. 
of a mixed effects model based on the binomial distribution are not easy to interpret, especially as regards random effects. It was therefore decided that for outcomes expressed as percentages, a model based on the normal distribution would be used. The subsequent validation of the model for all outcomes showed no strong evidence invalidating this approximation. Experimental conditions $(c)$, time at which different assessments were made during the day $(t)$, condition $\times$ time interaction $(c t)$, order of exposure to conditions $(o)$ and gender $(g)$ were included as fixed factors. Subjects $(S)$, groups $(G r)$, subjectxcondition interaction $(S C)$ and subjectxtime interaction $(S T)$ were included as random factors in the model. Since not all data were collected continuously, but rather repeatedly for several times at specific moments during the day, time was included as a fixed factor and not as a covariate. This is also because a possible effect of time is not necessarily a linear or second order effect. With the present design of experiments, a specific exposure condition always followed a specific other exposure condition except if the condition was imposed on Monday. This means that the subjectxcondition $(S C)$ interaction was confounded with the subjectxorder of exposure $(\mathrm{SO})$ interaction in the statistical model. These interactions were not differentiated in the model and are consequently referred to as $S C$.

The analyses were made in the software $\mathrm{R}$ using the package 1merTest; this package was specifically developed for automated mixed ANOVA modelling of sensory and consumer data. The package automatically investigates the necessary factors and incorporates them by sequentially removing non-significant terms in the mixed model (Kuznetsova et al., 2015). In the present analysis, the significance level $\alpha$ was set to 0.1 for the random factors and to 0.05 for the fixed factors of the model. JMP Pro 11 software was used to estimate least-square means (LS Means), standard error (SE) and 95\% confidence intervals (95\% CI) representing the effects for different factors. This software was also used to perform post-hoc analyses using Tukey's-HSD test, whose purpose is to compare differences between different levels of

This article is protected by copyright. All rights reserved. 
factors. The purpose of the present experiment was to examine the effects of condition, so only comparisons of conditions at the same time point and comparisons of time within the same condition are shown in the Results section.

\section{Results}

Table 2 shows that the measured conditions were close to the intended conditions listed in Table 1, except for the relative humidity, which was slightly but not significantly higher in the M3000 exposures compared with the other exposures, for the reasons given in the Methods section. During the experiments, the lighting level was $378 \pm 73$ Lux and the noise level was $48 \pm 0.5 \mathrm{~dB}(\mathrm{~A}) . \mathrm{CO}_{2}$ concentrations were slightly higher when the ventilation rate was restricted to increase levels of bioeffluents compared to the conditions when $\mathrm{CO}_{2}$ was added, but only by $4-6 \%$. Ozone measured in the chamber was slightly higher when the outdoor air supply rates were high, i.e. in B500, P1000 and P3000. No measurements of outdoor ozone levels were performed but the measurements obtained from the nearest outdoor monitoring station collecting ambient air pollution levels showed that outdoor ozone levels were about 30-36 ppb during the entire experiment (Table 2). The ozone concentration in the chamber was always lower than this and the corresponding indoor-to-outdoor ratios were $0.73,0.77,0.70,0.44$ and 0.08 at B500/P1000/P3000/M1000/M3000 respectively; the latter two ratios reflect the fact that air change rates in the chamber were changed from $24 \mathrm{~h}^{-1}$ to $5.2 \mathrm{~h}^{-1}$ and $1.3 \mathrm{~h}^{-1}$. No measurements were performed to observe whether this removal of ozone led to the production of contaminants that would otherwise not have been present in the chamber, due especially to reactions that could occur on skin surfaces or any surfaces soiled by human skin oils (Wisthaler and Weschler, 2010).

This article is protected by copyright. All rights reserved. 
Table 2 Measured conditions during exposures in the chamber (mean \pm standard deviation)

\begin{tabular}{cccccc}
\hline Condition & $\mathrm{CO}_{2}(\mathrm{ppm})$ & Temperature $\left({ }^{\circ} \mathrm{C}\right)$ & Humidity $(\%)$ & Indoor $\mathrm{O}_{3}(\mathrm{ppb})$ & Ambient $\mathrm{O}_{3}(\mathrm{ppb})$ \\
\hline B500 & $435 \pm 37$ & $23.8 \pm 0.1$ & $28 \pm 7$ & $22 \pm 13$ & $30 \pm 10$ \\
P1000 & $1083 \pm 37$ & $24.0 \pm 0.3$ & $30 \pm 3$ & $24 \pm 21$ & $31 \pm 15$ \\
P3000 & $3004 \pm 47$ & $23.9 \pm 0.2$ & $27 \pm 3$ & $23 \pm 15$ & $33 \pm 11$ \\
M1000 & $1124 \pm 75$ & $23.9 \pm 0.1$ & $30 \pm 3$ & $15 \pm 3$ & $34 \pm 5$ \\
M3000 & $3192 \pm 343$ & $23.8 \pm 0.1$ & $33 \pm 4$ & $3 \pm 2$ & $36 \pm 6$ \\
\hline
\end{tabular}

Fig. 4 shows the results for subjective perception of the environment in the chamber and perceived comfort for outcomes where the effect of condition or conditionxtime interaction was statistically significant. In the latter case, change of outcome over exposure time under different conditions is shown. More detailed results of statistical analysis are shown in Table S4 and Table S5 in the Supplementary Material. Fig. 4 shows that the acceptability of the air quality upon entering and re-entering the chamber with human bioeffluents at elevated levels was assessed to be lower than in the other three exposure conditions; ratings at M3000 were statistically significantly different from the other assessments except from those obtained at M1000. There were no significant differences in the acceptability of the air quality between background exposure (B500) and exposures to artificially raised $\mathrm{CO}_{2}$ concentrations $(\mathrm{P} 1000$ and P3000). The ratings of the acceptability of the air quality in the chamber with elevated levels of bioeffluents improved during exposures: significant differences $(\mathrm{P}<0.05)$ were found at the time of entering and re-entering compared to the time points when assessments were obtained during M3000. Assessments of odour intensity and air freshness were similar to the ratings of acceptability of air quality and provided further evidence that air quality was worse only during exposures to elevated levels of bioeffluents (M1000 and M3000). The acceptability of thermal conditions was lower during exposures to elevated levels of bioeffluents; significant differences $(\mathrm{P}<0.05)$ were observed at the beginning of exposure at

This article is protected by copyright. All rights reserved. 
M3000 compared to the other exposures except M1000. There were no significant differences in thermal sensation: subjects reported that they were generally slightly warmer than neutral (thermal sensation vote equal to 0.4) (Table S1 in Supplementary Material). The air in the chamber with elevated levels of bioeffluents was perceived by subjects to be more humid compared to background exposure and to exposures when pure $\mathrm{CO}_{2}$ was added (Fig. 4), even though it effectively was not more humid (see Table 2).

Fig. 5 shows the subjective assessments of acute health symptoms for which the effect of condition was statistically significant. The interaction condition $\times$ time was not significant for any of the self-assessed health symptoms. This means that the effects of exposure conditions on intensity of acute health symptoms were not associated with any particular time period, at which the assessments were made. Consequently, the least square means are presented in Fig. 5, which are not assigned to any specific time when the subjective ratings were obtained. More detailed results of statistical analysis are shown in Table S4 and Table S5 in the Supplementary Material. Fig. 5 shows that difficulty in thinking clearly, headache, fatigue and sleepiness were systematically more intense at M3000; however, the tendency is only statistically significant in some cases: for intensity of headache M3000 is statistically significantly different from B500 and P3000, for the other 3 symptoms M3000 is statistically significantly different from P1000. For difficulty in thinking clearly and intensity of fatigue, subjects reported higher intensity at M1000 compared to B500, P1000 or P3000, although this tendency was not statistically significant. Additionally, these four symptoms increased significantly over the course of exposure during the day and the change was independent of conditions.

This article is protected by copyright. All rights reserved. 

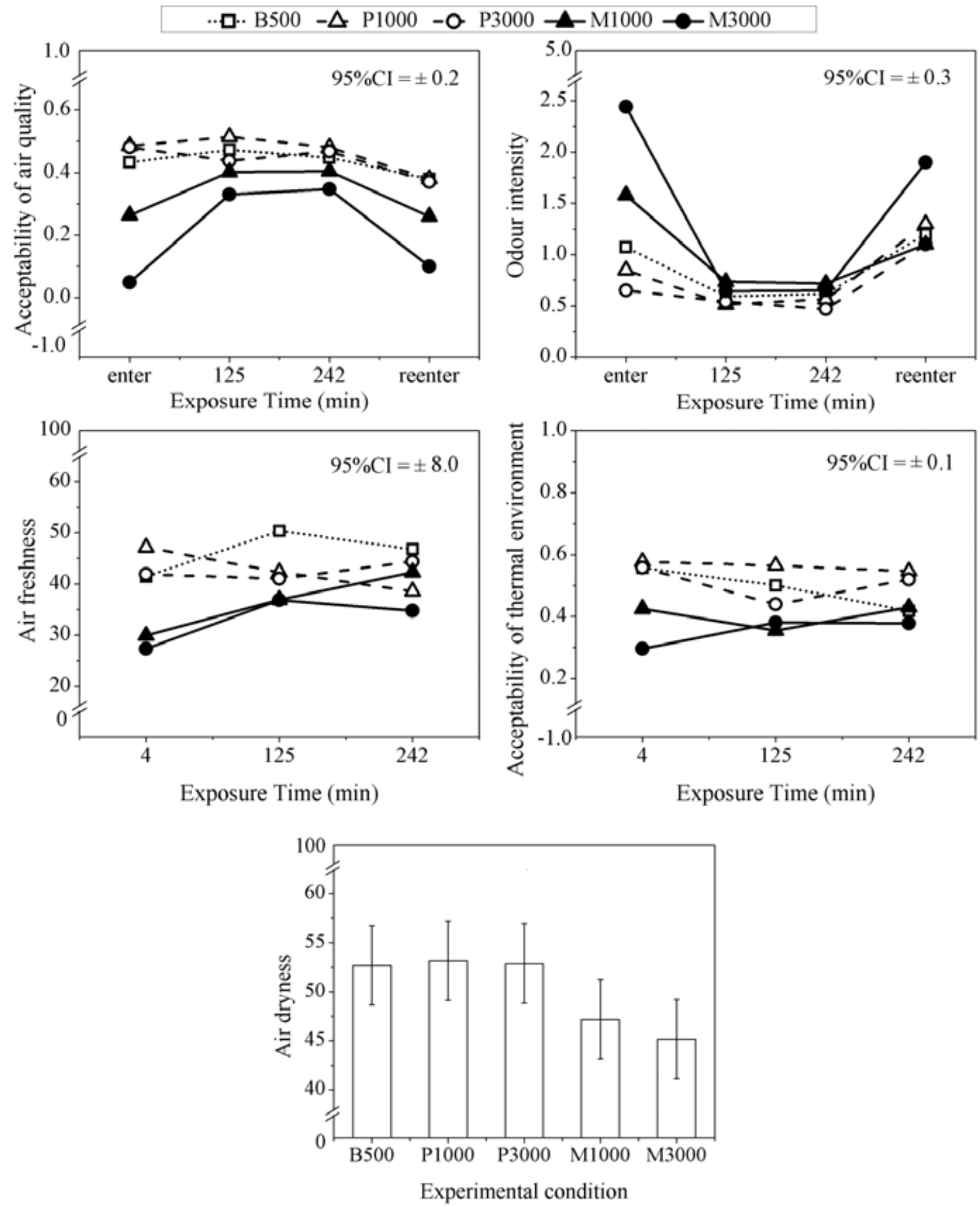

Fig. 4 Subjective perceptions of environment in the chamber and perceived comfort for outcomes where the effect of condition or conditionxtime was statistically significant; the error bars show the $95 \% \mathrm{CI}$ for the LS Means; the scales were coded as follows: for the assessment of acceptability, $-1=$ clearly unacceptable,$+1=$ clearly acceptable; for the assessment of odour intensity, $0=$ no odour, $1=$ slight odour, $2=$ moderate odour, $3=$ strong

This article is protected by copyright. All rights reserved. 
odour, 4=very strong odour, 5=overwhelming odour; for the assessment of air freshness,

$0=$ stuffy, $100=$ fresh; for the assessment of air dryness, $0=$ humid, $100=$ dry
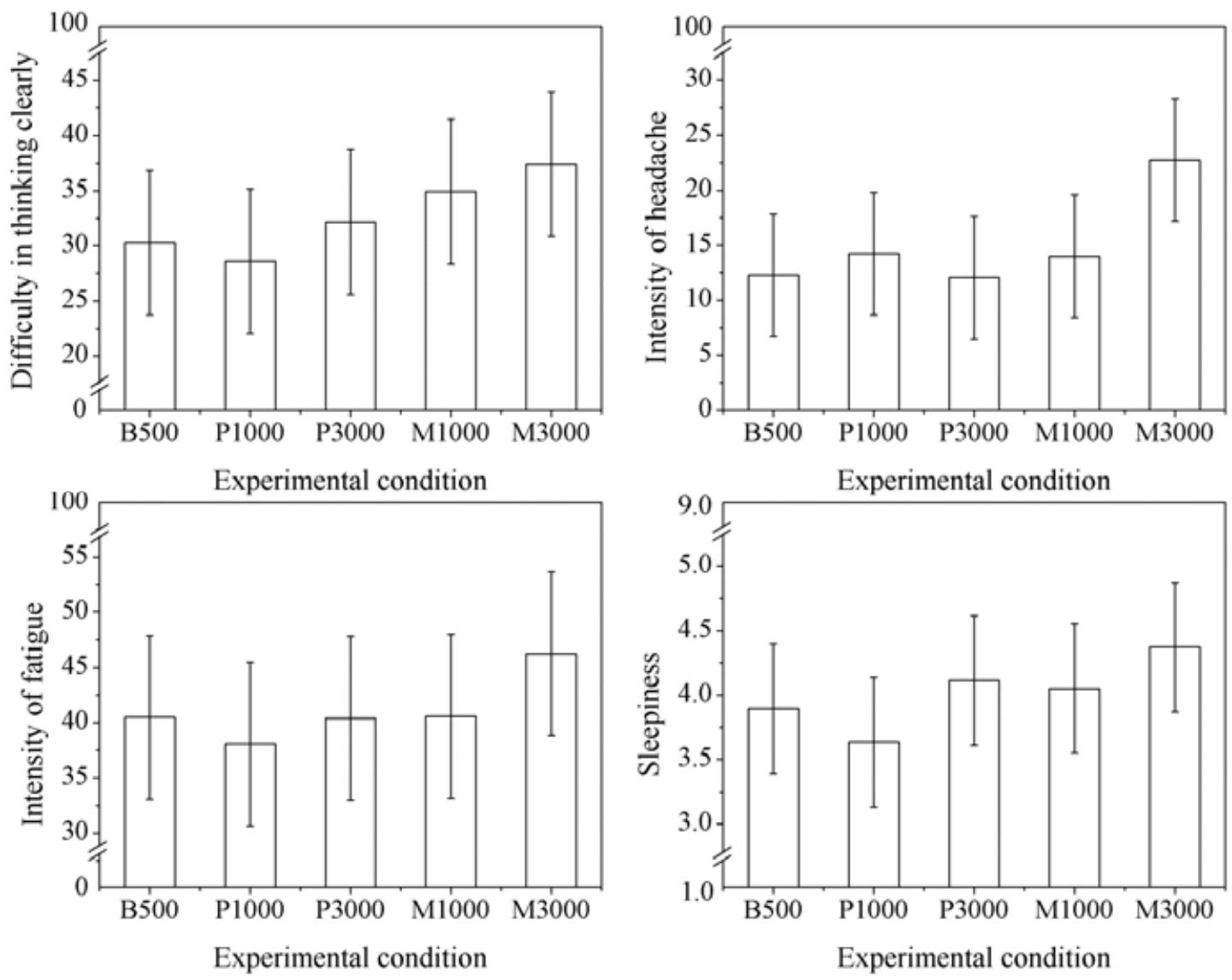

Fig. 5 Intensity of acute health symptoms for the effect of condition was statistically significant; the error bars show the 95\%CI for the LS Means; the scales were coded as follows: for the assessment of difficulty in thinking clearly, $0=$ easy, 100=hard; for the assessment of headache, $0=$ no headache, $5=$ severe headache; for the assessment of fatigue, $0=$ rested, 100=tired; for the assessment of sleepiness, $1=$ very alert, $9=$ very sleepy (see Fig. 2)

Fig. 6 shows the results of cognitive tasks, for which the effect of condition was statistically significant. The interaction condition $\times$ time was not significant for any of the tests/tasks used to examine mental performance, so like in the case of ratings of acute health 
symptoms, the results of mental performance (Fig. 6) are presented as the least square means and are not linked with any specific time when the tests/tasks were performed. More detailed results of statistical analysis are shown in Table S4 and Table S5 in Supplementary Material. Among the many tasks examining the impact of exposure conditions on the performance of subjects, there were only a few for which conditions had a significant effect on performance. These were addition (for speed, $\mathrm{P}=0.023$; for error rate, $\mathrm{P}=0.049$ ), redirection (for response time, $\mathrm{P}=0.015$ ) and the Tsai-Partington test (for number of correct links, $\mathrm{P}<0.001$ ).

Speed in the addition task was lower for all other conditions compared to B500; post-hoc analyses indicate that only the difference between M3000 and B500 was statistically significant (Fig. 6). For $\%$ of errors made in addition, even though condition is statistically significant ( $\mathrm{P}=0.049$ according to the F-test for condition in the mixed model), the post-hoc test for condition showed no significant differences. Such an apparent inconsistency between the F-test and the post-hoc test can sometimes appear in cases like this, where the P-value approaches 0.05 in the F-test. It is thus impossible to indicate in Fig. 6 in which pairs of conditions the significant differences existed.

The response time in the redirection test was lower indicating improved performance, at M3000 compared with the other conditions (Fig. 6), and the difference between P1000 and M3000 was statistically significant; there were no significant effects on errors in this test.

The results of the Tsai-Partington test showed that the number of correct links made by the subjects was lower for all other conditions compared with B500, indicating reduced cueutilisation capacity; the differences between B500 and M1000, and B500 and M3000 were statistically significant and the difference between P1000 and M1000 was also statistically significant (Fig. 6).

This article is protected by copyright. All rights reserved. 

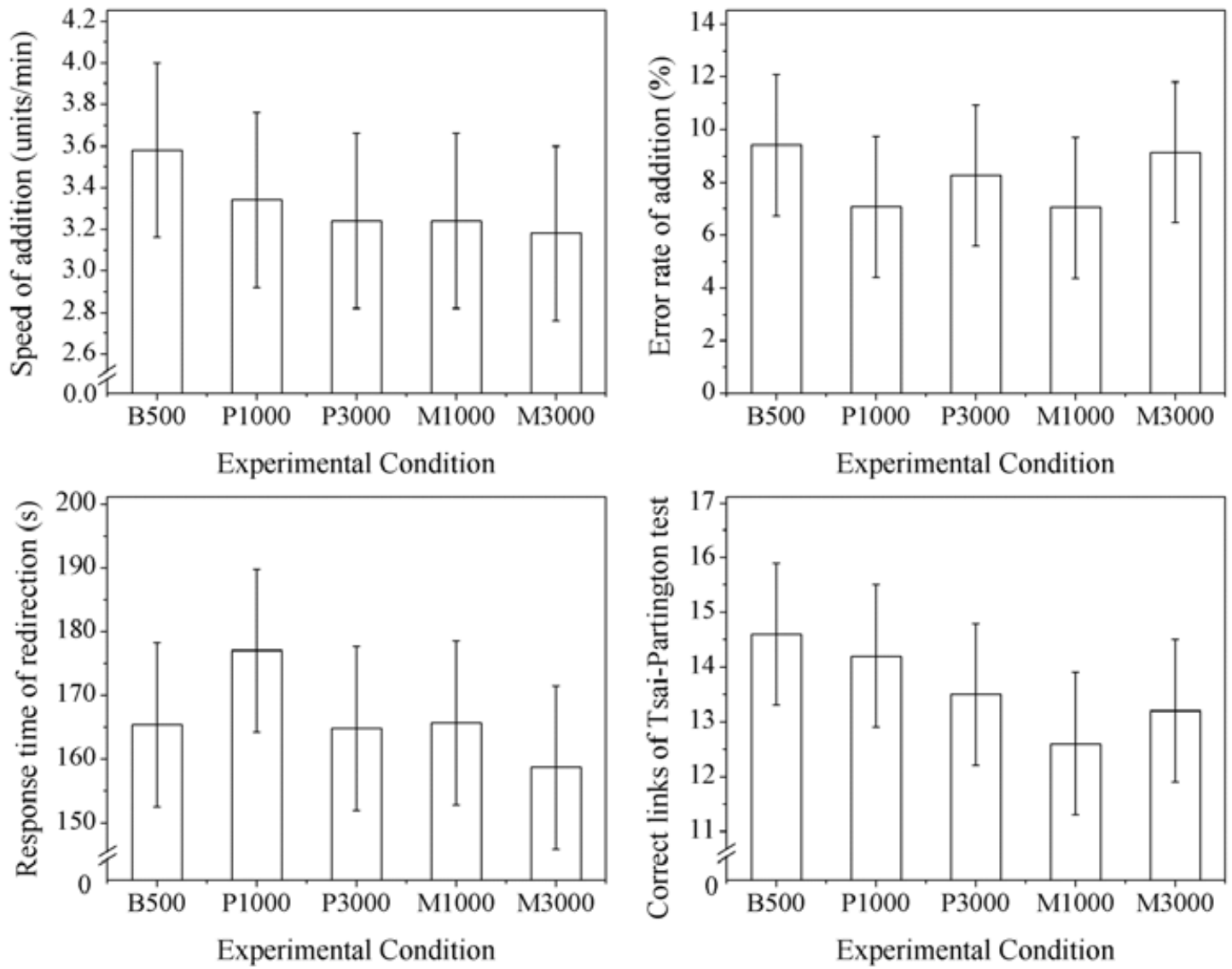

Fig. 6 Performance of tests for which the effect of condition was statistically significant. The error bars show the $95 \% \mathrm{CI}$ for the LS Means

A Tukey test for all significant pairwise differences between the conditions presented in Figs. 4-6 showed that M3000 was significantly different from either B500 or P1000 or P3000, and no other pairs of conditions were statistically significant from each other, except for odour intensity and air freshness assessments at M1000 being different from P1000. This may suggest that B500, P1000 and P3000 conditions were not different from each other and could be pooled during analyses. This was not done in the present analysis, which was of an exploratory nature and whose main purpose was to examine whether there are differences between the established conditions and in particular whether the P-conditions caused any changes in the ratings performed by the subjects.

This article is protected by copyright. All rights reserved. 


\section{Discussion}

The present results show that exposures to artificially raised $\mathrm{CO}_{2}$ up to 3,000 ppm did not cause significant changes in subjectively rated air quality, odour intensity, the intensity of acute health symptoms or the performance of a variety of tasks measuring the performance of different aspects of office work. This conclusion is made based on the results of statistical analyses showing that either condition (depicting exposure conditions) or condition $\times$ time interaction (depicting the change of outcomes along the course of exposure in different conditions) was not statistically significant when $\mathrm{CO}_{2}$ was added to the chamber air. These results were consistent across different outcomes and are plausible considering that $\mathrm{CO}_{2}$ is odourless, that the occupational exposure limit for $\mathrm{CO}_{2}$ is $5,000 \mathrm{ppm}$ and that previous studies show that toxic effects cannot be expected until $\mathrm{CO}_{2}$ levels reach at least 10,000 ppm (Law et al., 2010). Lack of any significant effects on perceived air quality, though likely, is contrary to the results obtained in the study by Kajtár and Herczeg (2012), in which exposure to $\mathrm{CO}_{2}$ up to $3,000 \mathrm{ppm}$ was observed to reduce the perceived air quality; this effect was however observed only in one experimental series in their study and was not confirmed in the replication experiments. The information regarding experimental protocols presented by Kajtár and Herczeg are insufficient to provide an explanation for their unexpected result and the authors themselves did not provide any explanation for this finding. Kajtár and Herczeg also reported that their 120-150 minute exposures to artificially raised $\mathrm{CO}_{2}$ levels of 3,000 ppm or higher resulted in increased fatigue, and in a significant decrement in wellbeing and the ability to maintain attention, but these effects were not found in the present experiment

Contrary to the findings reported by Kajtár and Herzecg (2012), Satish et al. (2012) and Allen et al. (2015), the present results did not show any significant effects of elevated $\mathrm{CO}_{2}$ exposures on cognitive performance. This is consistent with there being no significant effects

This article is protected by copyright. All rights reserved. 
on perceived comfort or acute health symptoms, as neuro-behavioural symptoms have been postulated as one of the most probable reason for effects on performance observed in nonindustrial environments (Bakó-Biró et al., 2005; Wyon and Wargocki, 2013). The test battery used by Satish et al. (2012) and Allen et al. (2015), known as the Strategic Management Simulation (SMS) (Streufert et al., 1988; Breuer et al., 2003; Satish et al., 2004), is designed to examine the effectiveness of management-level employees by exposing individuals to diverse situations based on the real-world equivalent challenges in complex decision-making. The tests included in this battery are much different and more complex than the simple cognitive tests and tasks resembling office work used in the present experiment. SMS imposes considerable cognitive load and requires many resources to solve complex and strategic problems. It can be thus postulated that differences in cognitive tasks and their difficulty is a plausible explanation of the discrepancy between the results of the three different experiments and it should be examined in the future experiments. That such need exits is further motivated by the results of the study by Kajtár and Herczeg (2012) who observed that elevated $\mathrm{CO}_{2}$ levels increased the number of errors in proof-reading, a much more common task that was also used in the present experiments but was not affected significantly by exposures to pure $\mathrm{CO}_{2}$.

The present results imply that exposure to increasing levels of bioeffluents representing by increasing $\mathrm{CO}_{2}$ up to $3,000 \mathrm{ppm}$ will reduce perceived air quality, increase odour intensity and the intensity of several neuro-behavioural symptoms such as headache and difficulty in thinking clearly, and cause subjects to feel more tired and more sleepy. These findings are plausible as they confirm many previous laboratory experiments concerning perceived air quality and odour intensity (e.g., Yaglou et al., 1936; Fanger and Berg-Munch, 1983) and show that at least some of the acute health symptoms observed in field experiments on office workers can be attributed to exposure to elevated levels of human bioeffluents (Seppänen et

This article is protected by copyright. All rights reserved. 
al., 1999). In many studies in schools, where the dominant sources of pollutants are the occupants, no effects on the intensity of symptoms were observed at moderate $\mathrm{CO}_{2}$ levels (Wargocki and Wyon, 2013), but the symptoms were assessed by children and not by adults as in the present study. Only high exposures, when $\mathrm{CO}_{2}$ was about 3,000 ppm or even higher, resulted in reports of increased intensity of symptoms among pupils (Myhrvold et al., 1996; Van Dijken et al., 2006), and only general symptoms were consistently affected.

The present results do not show that exposure to bioeffluents when $\mathrm{CO}_{2}$ is at or below 3,000 ppm would elevate acute health symptoms of irritation or dryness of the mucous membranes, respiratory tract or cutaneous symptoms. Whether this is incidental or a representation of a more general phenomenon is still to be determined.

Contrary to present results, Maddalena et al. (2015) did not observe any effects on perceived air quality during exposures to bioeffluents at $\mathrm{CO}_{2}$ levels as high as 1,800 ppm but their sensory evaluations of air quality were not made until after a full hour of exposure, by which time the subjects were probably already adapted to the reduced air quality; adaptation does occur quite quickly and is especially strong in the case of exposure to human bioeffluents (Gunnarsen and Fanger, 1992). Maddelena et al. (2015) used similar scales to register the intensity of symptoms as were used in the present experiments, but did not show any effects on symptoms. In fact, they observed a significant decrease of eye symptoms and a nearly significant decrease of fatigue and tiredness when bioeffluents were high, contrary to expectation. Only 16 subjects were included in their study, which may be insufficient to demonstrate significant differences. Additionally, the difference between low and high exposure level of bioeffluents may have been too small: the difference was 900 ppm compared to $2,500 \mathrm{ppm}$ in the present experiments. As suggested by these authors, there was a substantial proportion of prior symptoms among subjects, which could additionally contribute to the lack of effects on symptoms. The exposures to high level of bioeffluents 
occurred only during the last 3 hours of exposure while low exposures were experienced on one day, either in the morning or in the afternoon, so carry-over effects could influence the results even though the exposures were balanced between subject groups. The high level of prior symptoms may be considered as an indication of this effect.

In the study by Maddelena et al. (2015) exposures to bioeffluents caused significant effects on decision-making performance, but the effects were of a much lower magnitude compared to the study by Satish et al. (2012) which examined exposure to pure $\mathrm{CO}_{2}$ added to the chamber from a cylinder. Differences in the exposure level, the motivation of the subjects and in their skills and abilities could have caused the observed discrepancy.

The intensity of symptoms reported by the subjects in the present experiment increased monotonically with the level of bioeffluents (Fig. 7). More results are needed to validate this observation and to determine whether there is a threshold level of $\mathrm{CO}_{2}$ below which exposure to bioeffluents can be regarded as innocuous. Sarbu and Pacurar (2015) found that the performance of two diagnostic tests continued to improve linearly when bioeffluents levels reduced as indicated by a decrease of $\mathrm{CO}_{2}$ level from 1,000 to 500ppm, strongly indicating that there is no such threshold. Neither the present data (Fig. 4) nor the results of Maddelena et al. (2015) provide enough evidence on whether $\mathrm{CO}_{2}$ at or below 1,000 ppm can still be considered as an indicator of good indoor air quality in spaces where the occupants themselves are the main source of pollution. The present results indicate additionally that ensuring high levels of air quality with relatively low percentages dissatisfied with air quality will ensure that the intensity of symptoms will not increase and that performance will not be reduced, as would be expected.

The present results show that exposure to moderately elevated levels of bioeffluents may result in inferior cognitive performance. This is consistent with the evidence from previous laboratory experiments (Wargocki et al., 2000), field investigations (Wargocki et al., 2004)

This article is protected by copyright. All rights reserved. 
and school studies (Wargocki and Wyon, 2013), although these previous findings did not differentiate between the effects caused by exposure to bioeffluents and other pollutants, so the observed effects must be presumed to be of the combined effects of both. In the present experiment, the performance of only a few tasks was affected significantly during exposure to bioeffluents. Why so few tests were significantly affected in the present experiment cannot be explained, especially considering that subjects reported symptoms of headache and fatigue which are likely to affect performance (Bakó-Biró et al., 2005; Wyon and Wargocki, 2013), and that most of these tasks have previously been shown to be affected by either poor air quality or thermal discomfort (Wargocki et al., 1999, 2000; Lan et al., 2011). Response time in the redirection test was shorter when bioeffluents levels were higher, suggesting improved performance. This result could be due to higher arousal. That the arousal level was higher at elevated levels of bioeffluents is implied additionally by the reduced performance of the TsaiPartington test; this test requires a broad attentional field and thus a low level of arousal for efficient performance (Eysenck and Willett, 1962). According to arousal theory and the Yerkes-Dodson law, performance depends on arousal level and the nature of the test (Duffy, 1957). High arousal improves the performance of tests requiring concentration and visual attention (e.g., redirection test) but reduces the performance of mentally demanding tests involving rule-based logical thinking (e.g., addition).
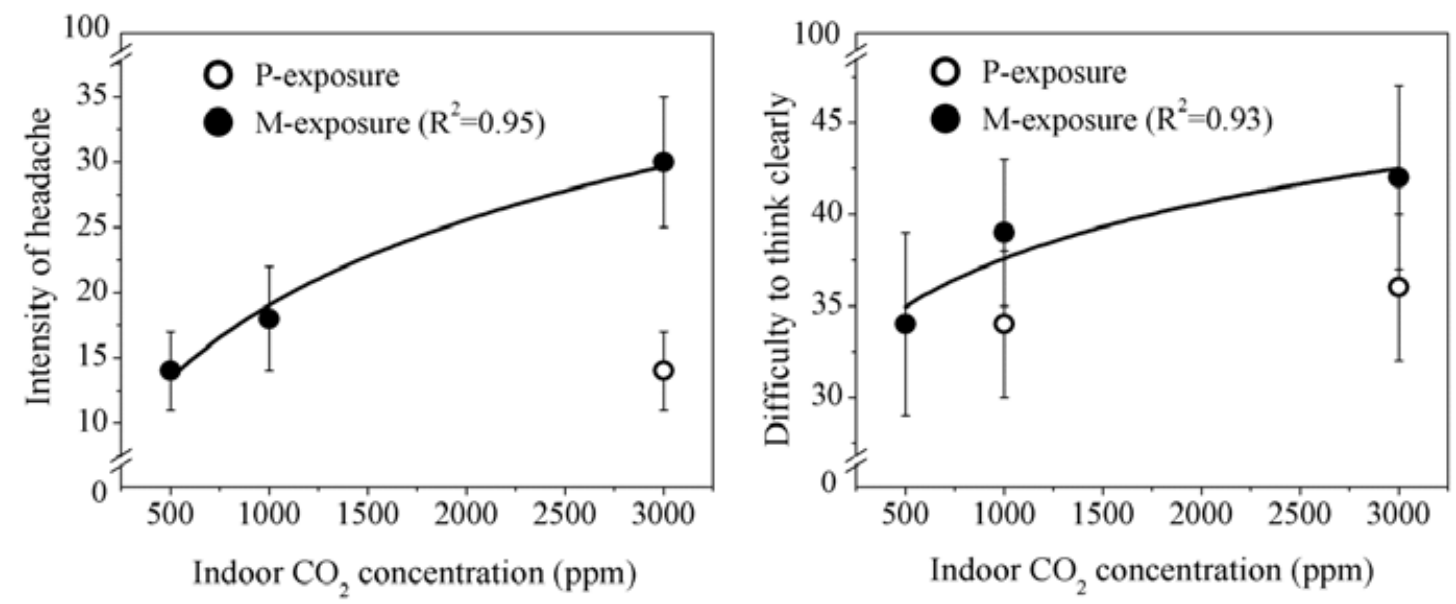

This article is protected by copyright. All rights reserved. 
Fig. 7 Exposure-response relationships for symptoms of mild headache and difficulty in thinking clearly during exposures to bioeffluents; intensity of symptoms during exposure to pure $\mathrm{CO}_{2}$ is indicated as well; $\mathrm{R}^{2}$ is coefficient of determination; error bars show $\mathrm{SE}$ for the descriptive means

Subjects reported that exposure to M3000 was significantly less acceptable than other exposures except M1000 in terms of the thermal conditions they encountered when they first entered the chamber, but there were no significant differences in thermal sensation. It is likely that subjects confused the perception of air quality with the perception of thermal condition, the two outcomes being closely related to each other. As shown by Fang et al. (1998a,b), both temperature and relative humidity affect the perception of air quality, most likely by altering the cooling effect of inhaled air on the mucous membrane (epithelia) in the nose, where the odour receptors are situated. It is possible that the effect is reciprocal and that a negative effect on perceived air quality may trigger a negative thermal response, resulting in unfavourable ratings of thermal conditions, and a general feeling of discomfort. In fact, early studies in the late XIX and early XX century, e.g. those cited in the report of the New York State Commission on Ventilation (1923), showed that insufficient ventilation (with high $\mathrm{CO}_{2}$ ) caused thermal discomfort and it was then postulated that ventilation rates could be kept low only if sufficient cooling was provided, poor ventilation being interpreted as overheating.

No chemical measurements were carried out to verify that the levels of pollutants in the empty chamber were low. This must be considered as an important limitation of the present work, but sensory measurements in the B500 condition (Fig. 4) show that the acceptability of the air quality was high, implying that the pollutant levels were indeed low. Another factor disturbing the present results during the M-exposures to bioeffluents could be the presence of

This article is protected by copyright. All rights reserved. 
pollutants emitted from subjects' clothing or created due to the reaction of ozone (not removed by charcoal filters) with human skin oils (Wisthaler and Weschler, 2010) especially since ventilation rates were reduced to achieve high $\mathrm{CO}_{2}$ levels. Ozone levels were lower in the M-conditions (Table 2), implying that such reactions could have taken place but no chemical measurements were carried out to verify this postulation. Previous work in a simulated airplane cabin showed that exposure to ozone at $60-80 \mathrm{ppb}$ with bioeffluents being a dominant pollution source and $\mathrm{CO}_{2}$ at levels up to 2,000 ppm can increase aching eyes, eye irritation, lip and skin dryness, headaches and dizziness (Weschler et al., 2007); only some of these effects (and none relating to the mucous membranes) were seen in the present experiments during M3000 exposures and at the much lower levels of ozone. This may suggest that the pollutants produced by reaction with ozone, if any, did not play an important role in the present experiments but the possibility cannot be completely ruled out.

Another limitation of the present work could be that among the subjects recruited for the experiments there were atopic persons as well as persons who considered themselves sensitive to indoor air quality. The results can be disturbed by responses of these subjects. For example, recent studies by Tham and Fadeyi (2015) and Fadeyi et al. (2015) show that atopic subjects are less sensitive to poor air quality, but they reported generally higher intensity of physiological symptoms such as flu, chest tightness and headache compared with non-atopic subjects. Their studies show also that when subjected to poor indoor air quality, atopic subjects performed concentration test significantly less well than the subjects without atopy. Besides, it is likely that individuals that are aware of their sensitivity may overestimate the true effects of environmental factors and/or may even compensate for these effects. Taking these evidence into account, it was examined whether the subjects having different sensitivity responded differently in the present experiment. Supplementary analyses were made using ratings of air quality, odour intensity, air freshness, acute healthy symptoms and the results of

This article is protected by copyright. All rights reserved. 
mental performance. No significant differences were observed between responses of sensitive subjects $(n=12)$ and the other subjects $(n=13)$ (data not shown in the present paper). No differences were observed either between responses of atopic $(n=8)$ and non-atopic $(n=17)$ subjects (data not shown in the present paper either). Thus, there is no indication that the results of the present experiments were biased by inclusion of atopic subjects and subjects who considered themselves to be sensitive to air quality. However, it must be pointed out that the number of atopic subjects was much lower than the number of non-atopic subjects, and that the order of presentation of exposures to these subjects was not balanced either. This could distort the results of these analyses. Future studies should pay careful attention to the selection of subjects in order to form coherent and firm conclusions.

The present results and the physiological responses measured in this experiment and reported in the companion paper by Zhang et al. (2016) make it possible to suggest hypothetical mechanisms underlying the negative effects on cognitive performance during exposures to elevated levels of bioeffluents and $\mathrm{CO}_{2}$. These hypothetical mechanisms are also presented in the companion paper by Zhang et al. (2016).

\section{Conclusions}

- Compared to $\mathrm{CO}_{2}$ at $500 \mathrm{ppm}$, exposure to added $\mathrm{CO}_{2}$ at or below 3,000 ppm did not cause any significant changes in perceived air quality, acute health symptoms or cognitive performance during 4.25-hour exposures.

- Compared to $\mathrm{CO}_{2}$ at 500 ppm, a reduced outdoor air supply rate that allowed bioeffluents to increase to levels, at which $\mathrm{CO}_{2}$ increased up to $3,000 \mathrm{ppm}$, significantly reduced the air quality perceived by visitors, increased the intensity of general (neuro-behavioural) acute health symptoms without increasing respiratory or mucous membrane symptoms, and affected cognitive performance, reducing the speed

This article is protected by copyright. All rights reserved. 
of addition, allowing fewer correct links to be made in a Tsai-Partington test of cueutilisation but causing a quicker response in a redirection task. These cognitive effects are all compatible with a bioeffluent-induced state of increased arousal.

- Future studies are needed to determine the threshold level at which bioeffluents have adverse effects on occupants, and to reveal the underlying mechanisms of effects of bioeffluents on perceived air quality, health symptoms and cognitive performance.

\section{Acknowledgements}

This work is supported by Bjarne Saxhof Foundation, Key Program of National Natural Science Foundation of China (51238005), the 12th Five Plan National Science and Technology Support Project of China (No. 2012BAJ02B05), COWI Foundation and S. C. Van Foundation. Thanks are due to Shu Yuan for the assistance during experiments. Claus Nordstrøm from the Danish Centre for Environment and Energy provided the urban monitoring data for ozone and our DTU colleague Professor David Wyon provided extensive comments on the manuscript.

\section{References:}

ACGIH (2011) Documentation of the Threshold Limit Values and Biological Exposure Indices, Cincinnati $\mathrm{OH}$, American Conference of Governmental Industrial Hygienists.

Åkerstedt, T. and Gillberg, M. (1990) Subjective and objective sleepiness in the active individual, Int. J. Neurosci., 52, 29-37.

Albrechtsen, O. (1988) Twin climatic chambers to study sick and healthy buildings. In: Proceedings of Healthy Buildings '88, Vol 3, pp. 25-30.

Allen, J.G., Macnaughton, P., Satish, U., Santanam, S., Vallarino, J. and Spengler, J.D. (2015) Associations of cognitive function scores with carbon dioxide, ventilation, and volatile organic compound exposures in office workers: a controlled exposure study of green and conventional office environments, Environ. Health Persp.

Apte, M.G., Fisk, W.J. and Daisey, J.M. (2000) Associations between indoor $\mathrm{CO}_{2}$ concentrations and sick building syndrome symptoms in U.S. office buildings: an analysis of the 1994-1996 BASE study data, Indoor Air, 10, 246-257.

ASHRAE (1997) ASHRAE Handbook Fundamentals, Atlanta GA, American Society of Heating, Refrigerating and Air Conditioning Engineers.

This article is protected by copyright. All rights reserved. 
ASHRAE (2013) Ventilation for Acceptable Indoor Air Quality, Atlanta GA, American Society of Heating, Refrigerating and Air Conditioning Engineers.

ASTM (2012) Standard Guide for Using Indoor Carbon Dioxide Concentrations to Evaluate Indoor Air Quality and Ventilation, West Conshohocken, The American Society for Testing and Materials(D6245-12).

Bakó-Biró, Z.S., Wargocki, P., Wyon, D.P. and Fanger, P.O. (2005) Poor indoor air quality slows down metabolic rate of office workers. In: Proceedings of Indoor Air 2005, Vol 1, pp.76-80.

Bakó-Biró, Z.S., Kochhar, N., Clements-Croome, D.J., Awbi, H.B. and Williams, M. (2008) Ventilation rates in schools and pupil's performance using computerized assessment tests, Build. Environ., 43, 362-367.

Bekö, G., Lund, T., Nors, F., Toftum, J.R. and Clausen, G. (2010) Ventilation rates in the bedrooms of 500 Danish children, Build. Environ., 45, 2289-2295.

Brickenkamp, R., Schmidt-Atzert, L. and Liepmann, D. (2010) Test d2-Revision: Aufmerksamkeits-und Konzentrationstest, Hogrefe.

Cable, A., Mysen, M. and Thunshelle, K. (2014) Can demand controlled ventilation replace space heating in office buildings with low heating demand? In: Proceedings of Indoor Air 2014.

Cain, W.S., Leaderer, B.P., Isseroff, R., Berglund, L.G., Huey, R.J., Lipsitt, E.D. and Perlman, D. (1983) Ventilation requirements in buildings:control of occupancy odour and tobacco smoke odour, Atmos. Environ., 17, 1183-1197.

Coley, D.A., Greeves, R. and Saxby, B.K. (2004) The effect of low ventilation rates on the cognitive function of a primary school class, Int. J. of Vent, 6, 107-112.

Duffy, E. (1957) The psychological significance of the concept of arousal or activation, Psychol. Rev., 64, 265-275.

Emmerich, S.J. and Persily, A.K. (2001) State of the Art Review of $\mathrm{CO}_{2}$ Demand Controlled Ventilation Technology and Application, DIANE Publishing.

EN (2007) Indoor Environmental Input Parameters for Design and Assessment of Energy Performance of Buildings Addressing Indoor Air Quality, Thermal Environment, Lighting and Acoustics, Brussels, CEN(EN 15251).

Erdmann, C.A., Steiner, K.C. and Apte, M.G. (2002) Indoor Carbon Dioxide Concentrations and Sick Building Syndrome Symptoms in the Base Study Revisted: Analyses of the 100 Building Dataset, Lawrence Berkeley National Laboratory.

Eysenck, H.J. and Willett, R.A. (1962) Cue utilization as a function of drive: An experimental study, Perceptual and motor skills, 15, 229-230.

Fadeyi M.O., Tham K.W. and Wu W.Y. (2015) Impact of asthma, exposure period, and filters on human responses during exposures to ozone and its initiated chemistry products. Indoor Air, 25, 512-522.

Fang, L., Clausen, G. and Fanger, P.O. (1998a) Impact of temperature and humidity on perception of indoor air quality during immediate and longer whole-body exposures, Indoor Air, 8, 276-284.

Fang, L., Clausen, G. and Fanger, P.O. (1998b) Impact of temperature and humidity on the perception of indoor air quality, Indoor Air, 8, 80-90.

Fanger, P.O. (1988) Introduction of the olf and the decipol units to quantify air pollution perceived by human indoors and outdoors, Energ. Buildings, 12, 1-6.

Fanger, P.O. and Berg-Munch, B. (1983) Ventilation and body odor. In: Proceedings of An Engineering Foundation Conference on Management of Atmospheres in Tightly Enclosed Spaces, pp. 45-50.

Gunnarsen, L. and Fanger, P.O. (1992) Adaptation to indoor air pollution, Energ. Buildings, 18, 43-54.

This article is protected by copyright. All rights reserved. 
Haverinen-Shaughnessy, U., Moschandreas, D.J. and Shaughnessy, R.J. (2011) Association between substandard classroom ventilation rates and students' academic achievement, Indoor Air, 21, 121-131.

Iwashita, G., Kimura, K., Tanabe, S., Yoshizawa, S. and Ikeda, K. (1990) Indoor air quality assessment based on human olfactory sensation, J. Archit. Plan. Environ. Eng., 410, 9-19.

Kajtár, L. and Herczeg, L. (2012) Influence of carbon-dioxide concentration on human wellbeing and intensity of mental work, Q. J. Hungari. Meteor. Serv., 116, 145-169.

Kuznetsova, A., Christensen, R.H.B., Bavay, C. and Brockhoff, P.B. (2015) Automated mixed ANOVA modeling of sensory and consumer data, Food Qual. Prefer., 40, 31-38.

Lan, L. and Lian, Z. (2010) Application of statistical power analysis - How to determine the right sample size in human health, comfort and productivity research, Build. Environ., 45, 1202-1213.

Lan, L., Wargocki, P. and Lian, Z. (2011) Quantitative measurement of productivity loss due to thermal discomfort, Energ. Buildings, 43, 1057-1062.

Law, J., Watkins, S. and Alexander, D. (2010) In flight carbon dioxide exposures and related symptoms: association, susceptibility, and operational implications, Houston, TX, NASA Johnson Space Center.

Levenshtein, V.I. (1966) Binary codes capable of correcting deletions, insertions, and reversals, Sov. Phys. Dokl., 10, 707-710.

Maddalena, R., Mendell, M.J., Eliseeva, K., Chan, W.R., Sullivan, D.P., Russell, M., Satish, U. and Fisk, W.J. (2015) Effects of ventilation rate per person and per floor area on perceived air quality, sick building syndrome symptoms, and decision-making, Indoor Air, 25, 362-370.

Masoli, M., Fabian, D., Holt, S., and Beasley, R. (2004) The global burden of asthma: executive summary of the GINA Dissemination Committee report. Allergy, 59, 469-478.

Menå, H. and Larsen, E. (2010) Indoor Environment in Schools, Technical University of Denmark.

Mendell, M.J., Eliseeva, E.A., Davies, M.M., Spears, M., Lobscheid, A., Fisk, W.J. and Apte, M.G. (2013) Association of classroom ventilation with reduced illness absence: a prospective study in California elementary schools, Indoor Air, 23, 515-528.

Milton, D.K., Glencross, P.M. and Walters, M.D. (2000) Risk of sick leave associated with outdoor air supply rate, humidification, and occupant complaints, Indoor Air, 10, 212-221.

Myhrvold, A. and Olesen, E. (1997) Pupils health and performance due to renovation of schools, In: Proceedings of Healthy Buildings/IAQ '97, Vol 1, pp. 81-86.

Myhrvold, A.N., Olsen, E. and Lauridsen,Ø. (1996) Indoor environment in schools - pupils health and performance in regard to $\mathrm{CO}_{2}$ concentrations. In: Proceedings of Indoor Air '96, Vol 1, pp. 369-374.

New York State Commission on Ventilation (1923) Ventilation: Report of the New York State Commission on Ventilation, New York, E.P. Dutton \& Co.

Norbäck, D., Nordström, K. and Zhao, Z.H. (2013) Carbon dioxide $\left(\mathrm{CO}_{2}\right)$ demand-controlled ventilation in university computer classrooms and possible effects on headache, fatigue and perceived indoor environment: an intervention study, Int. Arch. Occ. Env.Hea., 86, 199-209.

Partington, J.E. (1949) Detailed instructions for administering Partington's pathways test, Psychol. Serv. Cent. J., 1, 46-48.

Partington, J.E. and Leiter, R.G. (1949) Partington's pathways test, Psychol. Serv. Cent. J., 1, 11-20.

Pettenkofer, M.V. (1858) Über den Luftwechsel in Wohngebäuden, München, Cotta'schenbuchhandlung.

Ramalho, O., Wyart, G., Mandin, C., Blondeau, P., Cabanes, P.A., Leclerc, N., Mullot, J., Boulanger, G. and Redaelli, M. (2015) Association of carbon dioxide with indoor air pollutants and exceedance of health guideline values, Build. Environ.,

This article is protected by copyright. All rights reserved. 
http://dx.doi.org/10.1016/j.buildenv.2015.03.018.

Sarbu, I. and Pacurar, C. (2015) Experimental and numerical research to assess indoor environment quality and schoolwork performance in university classrooms. Build. Environ., 93, 141-154

Satish, U., Mendell, M.J., Shekhar, K., Hotchi, T., Sullivan, D., Streufert, S. and Fisk, W.J. (2012) Is $\mathrm{CO}_{2}$ an indoor pollutant? Direct effects of low-to-moderate $\mathrm{CO}_{2}$ concentrations on human decision-making performance, Environ. Health Persp., 120, 1671-1705.

Seppänen, O.A., Fisk, W.J. and Mendell, M.J. (1999) Association of ventilation rates and $\mathrm{CO}_{2}$ concentrations with health and other responses in commercial and institutional buildings, Indoor Air, 9, 226-252.

Shaughnessy, R.J., Haverinen-Shaughnessy, U., Nevalainen, A. and Moschandreas, D. (2006) A preliminary study on the association between ventilation rates in classrooms and student performance, Indoor Air, 16, 465-468.

Stricker, S., Bourgeau, M., Fconberg, E. and Pdarent, D. (1997) Physiological responses to elevated carbon dioxide levels in buildings, Indoor Built Environ., 6, 301-308.

Strøm-Tejsen, P., Zukowska, D., Fang, L., Space, D.R. and Wyon, D.P. (2008) Advantages for passengers and cabin crew of operating a gas-phase adsorption air purifier in 11-h simulated flights, Indoor Air, 18, 172-181.

Tham, K. W. and Fadeyi, M. O. (2015) Towards whom should indoor environmental quality control be sympathetic-Asthmatics or non-asthmatics?. Build. Environ., 88, 55-64.

Tsai, D.H., Lin, J.S. and Chan, C.C. (2012) Office workers' sick building syndrome and indoor carbon dioxide concentrations, J. Occup. Environ. Hyg., 9, 345-351.

Twardella, D., Matzen, W., Lahrz, T., Burghardt, R., Spegel, H., Hendrowarsito, L., Frenzel, A.C. and Fromme, H. (2012) Effect of classroom air quality on students' concentration: results of a cluster-randomized cross-over experimental study, Indoor Air, 22, 378-387.

Van Dijken, F., Van Bronswijk, J.E.M.H. and Sundell, J. (2006) Indoor environment and pupils' health in primary schools, Build. Res. Inf., 34, 437-446.

Wargocki, P. (2004) Sensory pollution sources in buildings, Indoor Air, 14, 82-91.

Wargocki, P. and Wyon, D.P. (2013) Providing better thermal and air quality conditions in school classrooms would be cost-effective, Build. Environ., 59, 581-589.

Wargocki, P., Wyon, D.P. and Fanger, P.O. (2004) The performance and subjective responses of call-center operators with new and used supply air filters at two outdoor air supply rates, Indoor Air, 14, 7-16.

Wargocki, P., Wyon, D.P., Baik, Y.K., Clausen, G. and Fanger, P.O. (1999) Perceived air quality, sick building syndrome (SBS) symptoms and productivity in an office with two different pollution loads, Indoor Air, 9, 165-179.

Wargocki, P., Wyon, D.P., Sundell, J., Clausen, G. and Fanger, P. (2000) The effects of outdoor air supply rate in an office on perceived air quality, sick building syndrome (SBS) symptoms and productivity, Indoor Air, 10, 222-236.

Weschler, C.J., Wisthaler, A., Cowlin, S., Tamás, G., Strøm-Tejsen, P., Hodgson, A.T., Destaillats, H., Herrington, J., Zhang, J.F. and Nazaroff, W.W. (2007) Ozone-initiated chemistry in an occupied simulated aircraft cabin, Environ. Sci. Technol., 41, 6177-6184.

Wisthaler, A. and Weschler, C.J. (2010) Reactions of ozone with human skin lipids: Sources of carbonyls, dicarbonyls, and hydroxycarbonylsin indoor air, P. Natl. Acad. Sci. USA, 107, 6568-6575.

Wyon, D.P. (1994) Symptom intensity feedback testing(SIFT): Behavioural science may be able to provide the key to curing sick buildings. In: Proceedings of Healthy Buildings'94, Vol 3, pp. 42-47.

Wyon, D.P. and Wargocki, P. (2013) How indoor environment affects performance, ASHRAE J., 55, 46-52.

This article is protected by copyright. All rights reserved. 
Yaglou, C.P., Riley, E.C. and Coggins, D.I. (1936) Ventilation requirements, ASHVE Trans., 42, 133-162.

Zhang, X.J., Wargocki, P. and Lian, Z.W. (2016) Physiological responses during exposure to carbon dioxide and bioeffluents at levels typically occurring indoors, Indoor Air (under review).

This article is protected by copyright. All rights reserved. 